\title{
CHANGES IN NERVE CONDUCTION WITH ULNAR LESIONS AT THE ELBOW
}

\author{
BY
}

\section{R. W. GILLIATT and P. K. THOMAS}

From the Department of Applied Electrophysiology, the National Hospital, Queen Square, London

Ulnar nerve lesions at the elbow can usually be recognized by a characteristic combination of physical signs. In the hand, there is wasting and weakness of ulnar-innervated muscles with or without sensory loss of appropriate distribution; in the forearm there is often weakness of the ulnarinnervated portion of the flexor digitorum profundus and sometimes of the flexor carpi ulnaris. Further confirmation may be provided by the presence of deformity or arthritic change in the elbow joint with palpable thickening of the nerve trunk in the ulnar groove. In such cases ancillary methods of diagnosis are seldom necessary, but in others the physical signs may be less obvious and any technique which assists localization deserves serious consideration.

Changes in motor nerve conduction in a patient with an ulnar nerve lesion at the elbow were first reported by Simpson (1956) who found that conduction was slowed through the affected region but that it was relatively normal both above and below it. A different approach to the study of nerve conduction was provided by the work of Dawson and Scott (1949) and Dawson (1956) on the direct recording of nerve action potentials, and Gilliatt and Sears (1958) showed that in patients with ulnar nerve lesions at the elbow abnormalities of the nerve action potential were present which might be particularly valuable in the diagnosis of mild cases.

Since January, 1956, we have studied 14 patients in each of whom the presence of an ulnar nerve lesion at the elbow was well established on clinical grounds. In these patients we have used the techniques developed by Simpson and by Dawson to study nerve conduction and our results form the subject of the present paper. In addition we have found it necessary to obtain more information about the range of normal variation and have made a series of control observations which will be described.

\section{Methods}

Details of the methods employed have been described by Gilliatt and Sears (1958) and Thomas, Sears, and Gilliatt (1959) and only a summary is given here.

Motor Nerve Conduction.-The ulnar nerve was stimulated with single shocks using surface electrodest placed on the skin over the nerve trunk. The stimulus was a brief condenser discharge locked to the time-base of the oscilloscope and delivered through an isolating transformer; its time constant was varied in different experiments from 50 to 150 microseconds with a voltage range of up to 300 volts. In the control subjects the stimulus intensity used was such that all motor nerve fibres to the muscle under examination were activated,

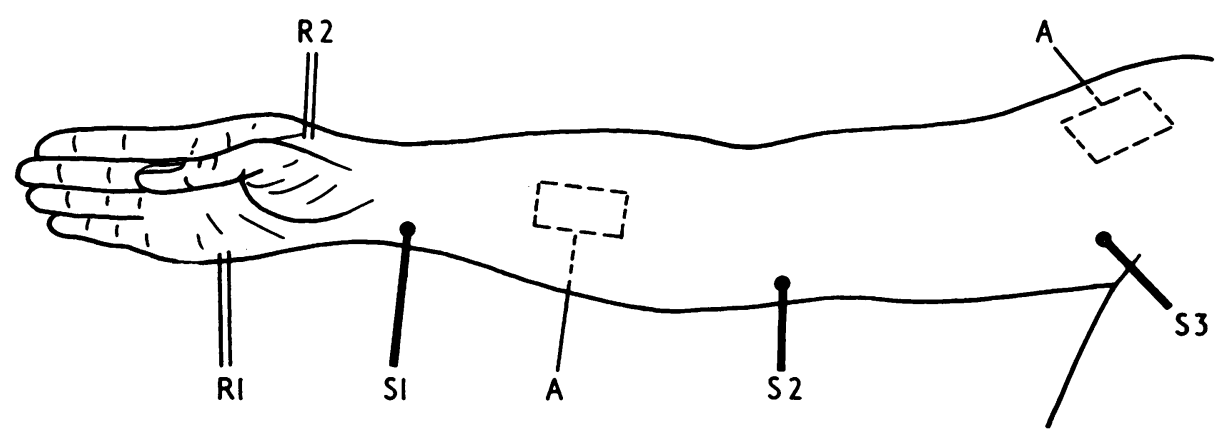

FIG. 1.-Diagram illustrating placement of stimulating and recording electrodes for measurement of motor nerve conduction time (for explanation, see text). 
but in some of the patients with ulnar lesions the electrical threshold was raised to an extent which made it impossible to stimulate more than a proportion of the nerve fibres even when using the maximum stimulus intensity tolerated by the patient. In every case the stimulating cathode was a pad electrode $1 \mathrm{~cm}$. in diameter and the anode a metal plate placed on the skin at a point remote from the nerve.

Three standard positions for the stimulating cathode were adopted (Fig. 1). The position S1 was at or just above the wrist; position $S 2$ was $3-6 \mathrm{~cm}$. above the medial epicondyle; position S3 was in the axilla. It is thus evident that although $\mathbf{S} 2$ may be referred to simply as the "elbow" stimulus, the segment of nerve between S1 and S2 includes that part of the nerve which lies in and just above the ulnar groove. In previous publications this has been referred to as the forearm segment, but it would be more correct to refer to it as the forearm-andelbow segment and, in order to avoid confusion, this latter term is used throughout the present paper. Interelectrode distance was measured on the surface of the limb; this must necessarily introduce some error, the importance of which has been discussed in a previous paper (Thomas et al., 1959).

The muscle response to nerve stimulation was recorded through a coaxial needle electrode placed in the abductor digiti minimi or the first dorsal interosseus muscle. After suitable amplification, muscle action potentials were displayed on one beam of a double-beam oscilloscope, the second beam being used to provide a time scale. The interval between the onset of the stimulus artefact and the initial deflection of the muscle action potential was measured from photographic records.
Recording of Nerve Action Potentials. - In most cases three separate segments of the ulnar nerve were examined (Fig. 2). For examining conduction between the fifth finger and the wrist, the digital nerves were stimulated through ring electrodes and the action potential of the afferent volley recorded by means of surface electrodes placed over the nerve trunk just above the wrist (Fig. 2A). Stimulation of the finger with recording above the elbow did not prove satisfactory owing to the small size of the potential obtained in normal subjects, and when examining conduction over the forearm-and-elbow segment, we have preferred to stimulate the nerve trunk at the level of the wrist (Fig. 2B). For this purpose the same wrist cathode was used as for motor stimulation (S1 in Fig. 1), the anode being a similar electrode placed on the hypothenar eminence. Surface recording electrodes were placed over the ulnar nerve just above the elbow with the lower recording electrode of the pair in the same position as the stimulating cathode $\mathbf{S 2}$ in Fig. 1; thus the wrist-elbow segment again included the elbow region itself. In order to examine ulnar nerve conduction above the suspected level of the lesion, the stimulating and recording positions shown in Fig. $3 \mathrm{C}$ were adopted, the stimulating cathode being in the same position as $\mathrm{S} 2$ in Fig. 1. With this arrangement, excessive stimulus artefact was sometimes troublesome and we found it advantageous to shave the axilla and place the recording electrodes as high as possible with the arm abducted to a right angle. With the recording electrodes in the apex of the axilla, potentials from the median and ulnar nerves could usually be recorded with equal facility and great care was necessary when placing the stimulating electrodes over the ulnar nerve just above

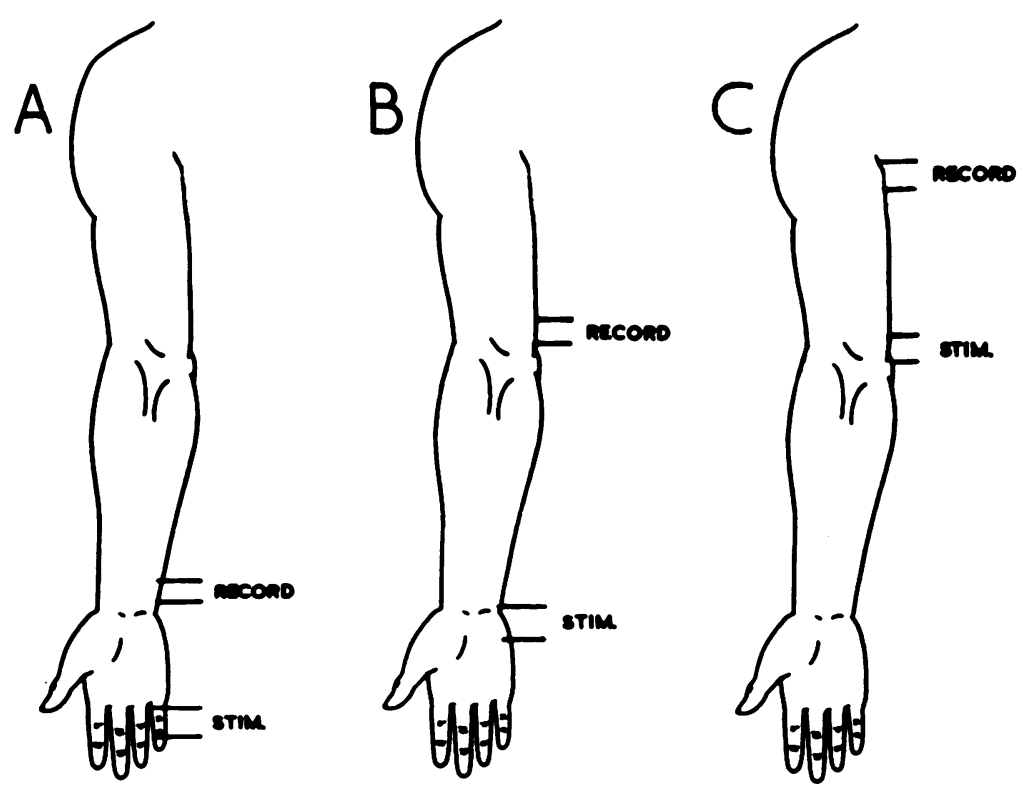

Fig. 2.-Diagram illustrating placement of electrodes for the recording of ulnar nerve action potentials (for explanation, see text). 
the elbow to avoid cross stimulation of the median nerve.

At all three levels in the limb, the surface recording electrodes used were of the same pattern as those described by Dawson and Scott (1949) with a fixed interelectrode distance of $3 \mathrm{~cm}$.

It will be clear from the preceding paragraphs that with the electrode arrangement shown in Fig. $2 \mathrm{~A}$ the potential recorded at the wrist is derived solely from impulses travelling in afferent fibres, whereas with the electrode arrangements shown in Figs. $2 \mathrm{~B}$ and $2 \mathrm{C}$, antidromic impulses in motor fibres also contribute to the recorded action potentials.

\section{Results in Control Subjects}

Although some control measurements of both motor and afferent nerve conduction were already available, we found it necessary to obtain further information about the range of normal variation particularly with regard to conduction in the upper arm. As before, control observations were made not only on healthy subjects working in the laboratory but also on the unaffected nerves of patients presenting isolated peripheral nerve lesions, no difference being found between the results obtained in staff and patients. The ages of the control subjects varied from 18 to 62 years, the age distribution being generally similar to that of our previous series (cf. Table II of Thomas et al., 1959).

Motor Conduction.--Results from the 15 subjects examined are shown in Table I, in which our previous control measurements are also summarized. From Table I it can be seen that whereas conduction time from the wrist to the first dorsal interosseous muscle was appreciably longer than from the wrist to the abductor digiti minimi (Ebeling, Gilliatt, and Thomas, 1960), the conduction velocity of the two groups of nerve fibres in the forearm did not differ significantly (Thomas et al., 1959). In the present series, conduction in fibres to the abductor digiti minimi was examined in 12 and in fibres to the first dorsal interosseous muscle in three subjects; in view of the small total number, results for all 15 are presented together in Table $I$ and it is satisfactory that the mean forearm velocity for this combined group agrees closely with the forearm values obtained previously.

In each of the 15 subjects in the present series, conduction velocity has been determined for the ulnar nerve in the upper arm as well as in the forearmand-elbow segment. For the upper arm, the range of conduction velocity was $50-73.9 \mathrm{~m}$. $/ \mathrm{sec}$. and the mean $59.8 \pm 6.1 \mathrm{~m}$. $/ \mathrm{sec}$., whereas for the forearm-and-elbow segment the range was $47 \cdot 5-64 \cdot 8$ $\mathrm{m} . / \mathrm{sec}$. with a mean of $54.5 \pm 5.5 \mathrm{~m}$. $/ \mathrm{sec}$. The difference between the means, although small, is statistically significant $(P=0.02)$.

Nerve Action Potentials.-For both the forearmand-elbow and the upper arm segments of the ulnar nerve, control observations were made in 15 subjects and on each occasion a diphasic or triphasic action potential was recorded. As in the digital nerve volleys described previously by Gilliatt and Sears (1958), the nerve action potential appeared rather abruptly with increasing stimulus strength, but $\underset{\omega}{N}$ above a certain critical stimulus intensity showed little further increase in action potential amplitudep $\omega$ It was emphasized by Gilliatt and Sears in relation $N$ to stimulation of the digital nerves that although 10 was not possible to deliver a supramaximal stimulu to a sensory nerve, it was perfectly feasible in normal subject to use a stimulus intensity sufficient to activate most of the large fibres in the ners trunk. Similar considerations apply when stimu․․․ lating a mixed nerve trunk at wrist or elbow leve $\vec{\theta}$ and in the present series stimulus intensity was always such that a further increase produced little change in the size of the response. Nerve action potential amplitude was found to vary considerably between subjects and, peak-to-peak measurements are shown in Fig. 3; values for the forearm-andelbow segment varied from 33 to 117 microvolts and for the upper arm segment from 33 to 100 microvolts. These figures may be compared with the range of 8 to 28 microvolts found by Gilliatt

TABLE I

MOTOR NERVE CONDUCTION IN CONTROL SUUJECTS

\begin{tabular}{|c|c|c|c|c|c|c|c|c|}
\hline \multirow{3}{*}{ Muscle } & \multirow{3}{*}{$\begin{array}{c}\text { No. } \\
\text { of } \\
\text { Subjects }\end{array}$} & \multirow{2}{*}{\multicolumn{2}{|c|}{$\begin{array}{c}\text { Latency (m.sec.) } \\
\text { Wrist-Muscle }\end{array}$}} & \multicolumn{4}{|c|}{ Conduction Velocity (m./sec.) } & \multirow{3}{*}{ Source } \\
\hline & & & & \multicolumn{2}{|c|}{ Elbow-Wrist } & \multicolumn{2}{|c|}{ Axilla-Elbow } & \\
\hline & & $\begin{array}{l}\text { Mean and } \\
\text { S.D. }\end{array}$ & Range & $\begin{array}{l}\text { Mean and } \\
\text { S.D. }\end{array}$ & Range & $\begin{array}{l}\text { Mean and } \\
\text { S.D. }\end{array}$ & Range & \\
\hline $\begin{array}{l}\text { Abd. dig. min. } \\
\text { First dors. inteross. } \\
\text { Abd. dig. min. } \\
\text { First dors. inteross. } \\
\text { Abd. dig. min. and first } \\
\text { dors. inteross. (mixed) }\end{array}$ & $\begin{array}{l}50 \\
50 \\
46 \\
49 \\
15\end{array}$ & $\begin{array}{l}2.9 \pm 0.4 \\
3 \cdot 8 \pm 0.5\end{array}$ & $\begin{array}{l}2 \cdot 0-3 \cdot 7 \\
3 \cdot 0-5 \cdot 0\end{array}$ & $\begin{array}{l}56 \cdot 2 \pm 4.6 \\
55 \cdot 0 \pm 4.9 \\
54 \cdot 5 \pm 5 \cdot 5\end{array}$ & $\begin{array}{l}49 \cdot 0-65 \cdot 6 \\
46 \cdot 2-66 \cdot 2 \\
47 \cdot 5-64 \cdot 8\end{array}$ & $59 \cdot 8 \pm 6 \cdot 1$ & $50 \cdot 0-73 \cdot 9$ & $\begin{array}{l}\text { Ebeling et al. (1960) } \\
\text { Thomäs et al. (1959) } \\
\text { Present series }\end{array}$ \\
\hline
\end{tabular}




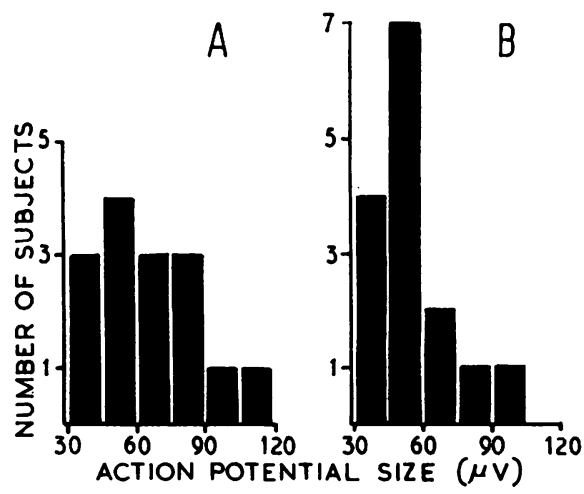

FIG. 3.-Distribution of ulnar nerve action potential amplitude in 15 control subjects. A. With stimulation at the wrist and recording above the elbow. B. With stimulation above the elbow and recording in the axilla.

and Sears when stimulating the fifth finger and recording from the ulnar nerve at the wrist.

In our present series we have again measured nerve action potential latency from the start of the stimulus artefact to the peak of the main (negative) deflection of the action potential, and in Fig. 4 these values have been plotted to show their relationship to conduction distance.

\section{Results in Patients with Ulnar Nerve Lesions}

Out of a total of 51 suspected ulnar nerve lesions referred for routine electromyography in the threeyear period 1956-59, there were 14 patients in whom the lesion could be placed at the elbow with considerable confidence on clinical grounds alone. In 10 of these 14 patients the ulnar nerve was explored surgically and found to show obvious pathological changes; in each of the remaining four patients, palpable thickening of the nerve behind the elbow was noted on clinical examination. Radiographic abnormalities of the elbow joint were present in 12 patients and varied from mild osteoarthritic changes to gross deformities associated with old fractures. In all 14 patients there was wasting of the ulnar-supplied muscles in the hand and sensory loss of characteristic distribution was present in all but one. Weakness of the ulnar-supplied portion of the flexor digitorum profundus proved a rather disappointing localizing sign which was clearly present in only eight of the 14 patients. The clinical, radiographic, and operative findings in the individual cases are summarized in the Appendix.

Motor Nerve Conduction.--Results in the 14 patients examined are presented in Table II. In three patients who were seen at an early stage of the investigation, nerve stimulation in the axilla was not performed so that no estimate of conduction velocity in the upper arm can be made. In one other patient (Case XIII) the lesion was so severe that the ulnar nerve was inexcitable at the wrist although a muscle response to nerve stimulation above the elbow was present. In this patient, therefore, it is not possible to give a value for conduction velocity for the forearm-and-elbow segment. In each of the remaining 11 patients stimulation was performed at all three levels in the arm and both conduction times and calculated velocities are shown in Table II.

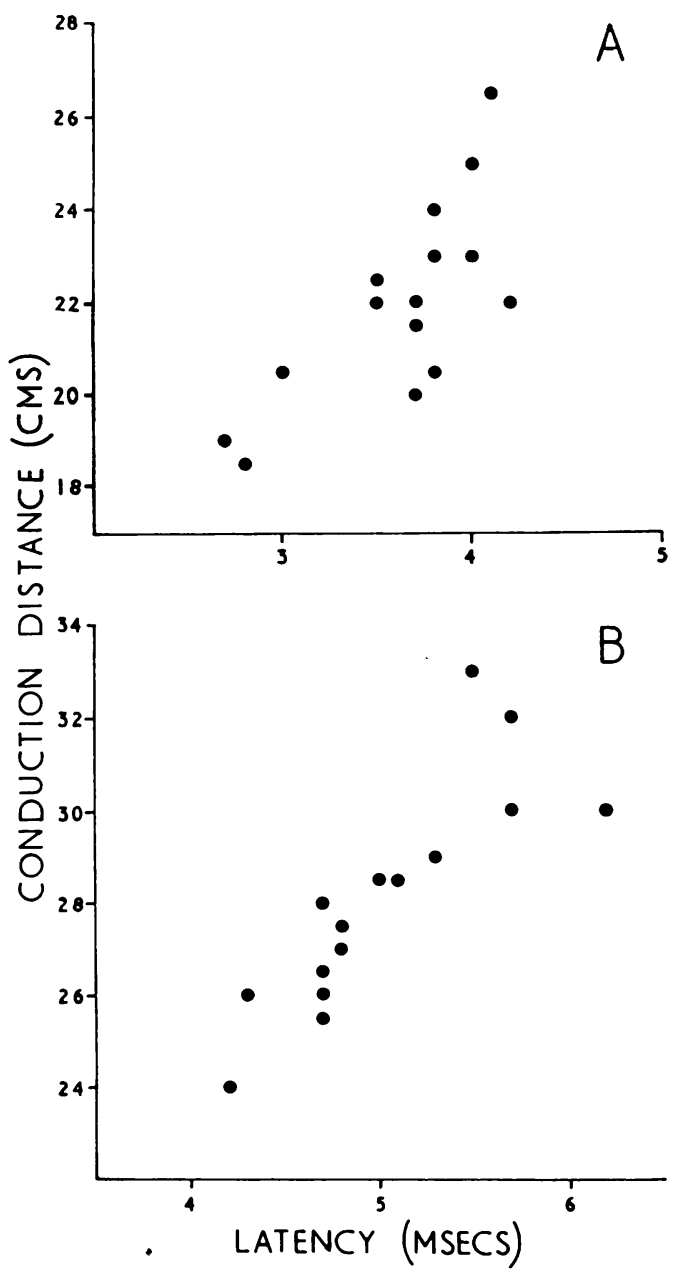

FIG. 4.-Relationship between uinar nerve action potential latency (measured to peak) and conduction distance (stimulating cathode to lower recording electrode) in 15 control subjects. A. With stimulation above the elbow and recording in the axilla. B. With stimulation at the wrist and recording above the elbow. 
TABLE II

MOTOR NERVE CONDUCTION IN PATIENTS WITH ULNAR NERVE LESIONS

\begin{tabular}{|c|c|c|c|c|c|c|}
\hline \multirow{2}{*}{ Case } & \multirow{2}{*}{ Muscle } & \multicolumn{3}{|c|}{ Latency (m.sec.) } & \multicolumn{2}{|c|}{ Conduction Velocity (m./sec.) } \\
\hline & & Wrist-Muscle & Elbow-Muscle & Axilla-Muscle & Elbow-Wrist & Axilla-Elbow \\
\hline $\begin{array}{l}\text { I } \\
\text { III } \\
\text { III } \\
\text { IV } \\
\text { VI } \\
\text { VII } \\
\text { VIII } \\
\text { IXX } \\
\underset{\text { XI }}{\text { XII }} \\
\text { XIII } \\
\text { XIV }\end{array}$ & $\begin{array}{l}\text { Abd. dig. min. } \\
\text { 1st dors. inteross. } \\
\text { Abd. dig. min. } \\
\text { First dors. inteross. } \\
\text { Abd. dig." min. } \\
\text { First dors. inteross. } \\
\text { ", } \\
\text { Abd. dig."min. } \\
\text { ", } \\
\text { First dors. inteross. }\end{array}$ & $\begin{array}{r}5 \cdot 0 \\
5 \cdot 8 \\
4 \cdot 4 \\
4 \cdot 8 \\
4 \cdot 5 \\
3 \cdot 5 \\
6 \cdot 3 \\
6 \cdot 8 \\
5 \cdot 0 \\
3 \cdot 7 \\
11 \cdot 0 \\
3 \cdot 4 \\
5 \cdot 2\end{array}$ & $\begin{array}{r}14.0 \\
18.5 \\
15.4 \\
17.2 \\
11.4 \\
9.4 \\
14.0 \\
16.5 \\
13.0 \\
13.0 \\
23.8 \\
12.0 \\
36.0 \\
12.5\end{array}$ & $\begin{array}{l}\overline{21 \cdot 8} \\
19 \cdot 4 \\
21 \cdot 8 \\
14 \cdot 5 \\
12 \cdot 6 \\
17 \cdot 0 \\
20 \cdot 0 \\
17 \cdot 0 \\
\overline{-} \\
15 \cdot 4 \\
40 \cdot 0 \\
16 \cdot 1\end{array}$ & $\begin{array}{l}31 \cdot 1 \\
23 \cdot 2 \\
23 \cdot 6 \\
22 \cdot 6 \\
39 \cdot 1 \\
50 \cdot 8 \\
32 \cdot 5 \\
28 \cdot 9 \\
37 \cdot 5 \\
29 \cdot 6 \\
23 \cdot 1 \\
34 \cdot 9 \\
4 \overline{43 \cdot 2}\end{array}$ & $\begin{array}{l}5 \overline{51 \cdot 5} \\
42 \cdot 5 \\
37 \cdot 0 \\
48 \cdot 4 \\
64 \cdot 1 \\
63 \cdot 3 \\
57 \cdot 1 \\
40 \cdot 0 \\
- \\
64 \cdot 7 \\
35 \cdot 0 \\
54 \cdot 2\end{array}$ \\
\hline
\end{tabular}

When the conduction times in Table II are compared with those of the control group, it is clear that in the patients there is diffuse slowing of conduction in the ulnar nerve, this change being most obvious in the forearm-and-elbow segment. Over this segment, our control subjects showed conduction velocities which were invariably more than $45 \mathrm{~m}$./sec. whereas velocities of less than this figure were recorded in 12 out of 13 patients, values of less than $25 \mathrm{~m}$./sec. being seen in four of them. In only one patient was forearm velocity within the normal range.

In the preceding paragraph results were expressed in terms of conduction velocity in order to eliminate variation due to the length of the forearm. Distal to the wrist, however, differences in conduction distance between individuals are less important and for this segment a direct comparison may be made between the latencies of the patients and those of the control subjects. In the patients, slowing was seen less often than in the forearm, but was definitely present in seven cases, in each of whom the latency exceeded the upper limit of the normal range. In the remaining six patients latencies were within the normal range but consistently above the mean.

In the upper arm, conduction velocity varied from 35 to $65 \mathrm{~m}$. $/ \mathrm{sec}$. with a mean of $50.7 \mathrm{~m}$. $/ \mathrm{sec}$. Compared with the normal mean of $59.8 \mathrm{~m}$./sec. there is thus some slowing in our patients; the difference between the means is not large but is statistically significant $(P=0.01)$.

Illustrative tracings, taken from Case III, are shown in Fig. 5. In this patient, the co-axial needle electrode used for recording the muscle action potential was placed in the abductor digiti minimi; the actual latency with wrist stimulation was $4.4 \mathrm{~m} . \mathrm{sec}$. and with stimulation just above the elbow, $15.4 \mathrm{~m} . \mathrm{sec}$; by subtraction, the figure $11.0 \mathrm{~m} . \mathrm{sec}$. is obtained which represents the conduction time between the elbow and wrist electrodes.
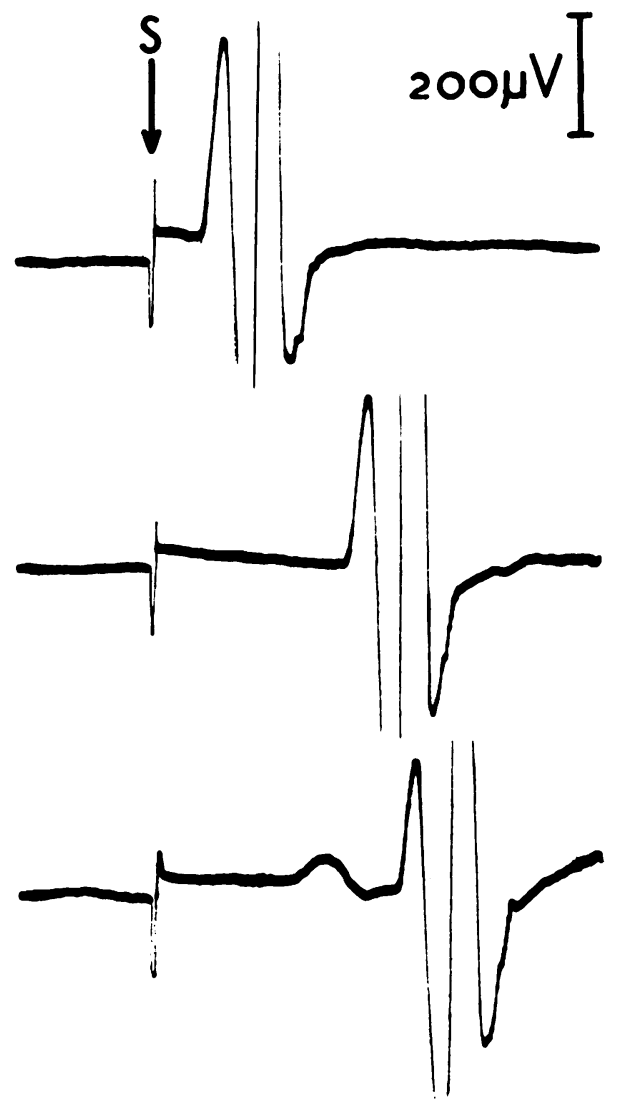

Iomsec

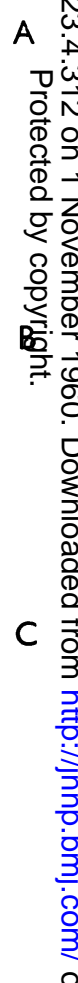

FIG. 5.-Recordings from the abductor digiti minimi in Case III, with stimulation of the ulnar nerve at the wrist (A), just above the elbow (B), and in the axilla (C). Stimulus at $S$ shown by artefact in each trace. The small early deflection in trace $C$ is due to spread of action potentials from median supplied hand muscles which are also activated when stimulating in the axilla. 
The inter-electrode distance, as measured on the surface of the arm, was $26.0 \mathrm{~cm}$., and thus the calculated velocity for this segment is $23.6 \mathrm{~m}$./ $/ \mathrm{sec}$., which may be contrasted with the figure of $42.5 \mathrm{~m}$. $/ \mathrm{sec}$. obtained in the same way for the segment of nerve in the upper arm.

In Case XIII, motor nerve conduction was considerably slower than in any of the other patients and a brief account of the clinical and electrical findings in his case may be of interest.

The patient, a man of 40 , was first seen in February, 1959 , with an 18-month history of increasing weakness of the left hand accompanied by loss of sensation on the medial side of the hand. At the age of 4 the patient had sustained a fracture of the left elbow which had left him with a markedly increased carrying angle and $30^{\circ}$ limitation of extension. Neurological examination in February, 1959, revealed severe wasting and weakness of the ulnar-supplied muscles in the left hand and superficial sensory loss to pin-prick and cotton wool of appropriate distribution. Wasting and weakness of the flexor carpi ulnaris and the ulnar-supplied portion of the flexor digitorum profundus were present and radiographs showed gross deformity of the elbow joint.

Electromyography was performed on March 31, 1959. On sampling the left abductor digiti minimi, scanty fibrillation was seen and only one motor unit under voluntary control could be found. With the needle in situ, the ulnar nerve trunk was stimulated at wrist level but no response was obtained, even when stimulus intensity was increased to the maximum tolerated by the patient. The ulnar nerve was then stimulated in the upper arm, the level of the stimulus being $9 \mathrm{~cm}$. above the tip of the olecranon; a third stimulus was applied to the nerve close to the axilla, the distance between the two cathode positions being $14 \mathrm{~cm}$. At both levels above the elbow the same single motor unit was activated, the latency from the lower stimulus being $36 \mathrm{~m} . \mathrm{sec}$. and from the upper stimulus $40 \mathrm{~m} . \mathrm{sec}$. Thus the latency of the muscle response with stimulation just above the elbow was increased to about three times the normal value and there was only a small additional delay when the stimulating cathode was moved up to the axilla.
However, the calculated velocity of $35 \mathrm{~m} . / \mathrm{sec}$. for the ulnar nerve in the upper arm indicates that mild slowing of nerve conduction was also present above the level of the lesion.

At operation on April 3, 1959, Mr. Harvey Jackson found the ulnar nerve to be " splayed out and thickened and surrounded by a fair amount of fibrous tissue".

Nerve Action Potentials.-Results for the whole group are shown in Table III. The fifth finger was stimulated through ring electrodes in nine patients but although stimulus intensity was increased to the maximum tolerated in each case, no action potentials could be detected by surface electrodes placed on the skin over the nerve trunk at the wrist. In eight patients the nerve was stimulated at the wrist and an attempt made to record the action potential of the afferent volley above the elbow, but again no potentials were seen, although the intensity of the stimulus at the wrist was sufficient in each case to produce a substantial motor response in the hand.

The ulnar nerve was stimulated above the elbow in six patients and in each a nerve action potential was successfully recorded from the axilla. In two patients the axillary potentials were small when compared with the potentials obtained in the control group. In the remainder the potentials were of normal amplitude and in all six cases their latencies were within the normal range.

A typical result taken from Case VIII is shown in Fig. 6, in which the flat tracings obtained at two levels below the lesion may be contrasted with the nerve action potential of normal size and latency recorded from the axilla.

\section{Discussion}

It was noted in our control series that there was a small but significant difference in motor nerve conduction velocity between the upper arm and the forearm-and-elbow segment, the former showing

TABLE III

NERVE ACTION POTENTIALS IN PATIENTS WITH ULNAR NERVE LESIONS

\begin{tabular}{|c|c|c|c|c|c|}
\hline \multirow{2}{*}{ Case } & \multirow{2}{*}{ Finger-Wrist } & \multirow{2}{*}{ Wrist-Elbow } & \multicolumn{3}{|c|}{ Elbow-Axilla } \\
\hline & & & Amplitude $(\mu \mathrm{V})$ & Latency (m.sec.) & Conduction Distance $(\mathrm{cm})$. \\
\hline 1 & - & - & $\overline{50}$ & - & - \\
\hline II & Absent & Absent & 50 & $\overline{2 \cdot 6}$ & $\overline{15 \cdot 0}$ \\
\hline III & Absent & Absent & $\underline{-}$ & $=$ & - \\
\hline $\mathrm{v}$ & Absent & Absent & $\overline{34}$ & $\overline{2 \cdot 5}$ & $1 \overline{3 \cdot 5}$ \\
\hline VI & Absent & Absent & 27 & $3 \cdot 6$ & 20.5 \\
\hline VIII & Absent & Absent & $\overline{92}$ & $\overline{3.6}$ & $20 \cdot 0$ \\
\hline IX & Absent & Absent & 35 & $2 \cdot 8$ & 17.0 \\
\hline$\underset{\mathbf{X}}{\mathbf{X}}$ & Absent & Absent & - & - & - \\
\hline$\hat{X I I}$ & Absent & E & 二 & 二 & - \\
\hline XIII & - & - & - & 二 & 二 \\
\hline XIV & Absent & Absent & 8 & 3.7 & 19.5 \\
\hline
\end{tabular}




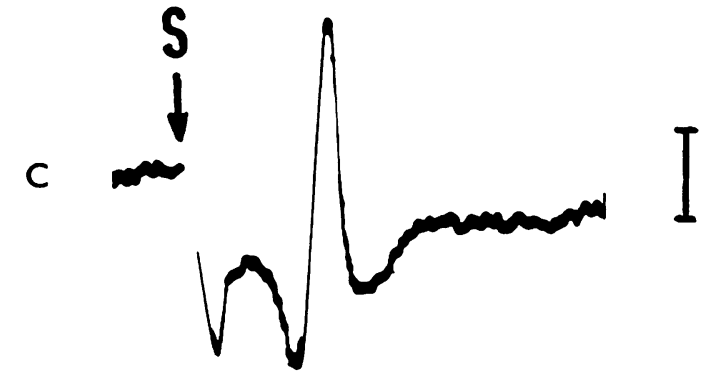

B

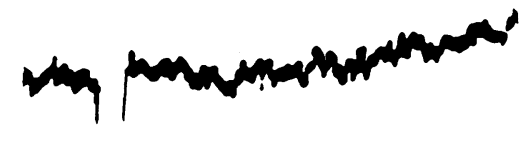

A
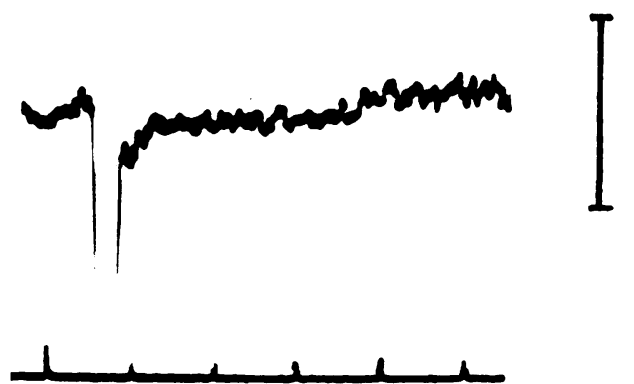

FIG. 6.-Case VIII. Ulnar nerve action potentials recorded with electrodes in the positions $\mathrm{A}, \mathrm{B}$, and $\mathrm{C}$ shown in Fig. 2. In positions $A$ and $B$, tracings show stimulus artefact at $S$ but no action potentials; in position $\mathrm{C}$ a normal potential follows stimulus artefact. Calibration mark indicates $25 \mu \mathrm{V}$ in each case. Time scale: $2 \mathrm{~m}$. sec. intervals.

a slightly higher velocity than the latter. This result agrees closely with the findings of Redford (1958) who reported a difference in mean conduction velocity between the upper arm and forearm of similar magnitude. This difference may be due to cooling of the ulnar nerve in the elbow region where it occupies a superficial position. However, no significant difference between the upper arm and forearm was apparent in the results of Norris, Shock, and Wagman (1953) and this point requires further study. In any case, the difference in conduction velocity found by Redford and ourselves is so small that it is unlikely to cause confusion in interpreting the results from patients with nerve lesions.
In our patients with ulnar lesions, the most constant finding has been a substantial reduction in conduction velocity in the forearm and elbow region, with more variable slowing of conduction distal to the wrist. In this respect it is interesting that in the single patient described by Simpson (1956) slowing was confined to the region of the elbow itself. It might be expected that slowing distal to the wrist would only be found in the most severely affected patients but the present series is not large enough to establish this point with certainty.

The mild degree of slowing found in the upper arm has several possible explanations. The simplest of these would be that with a traumatic neuroma at the elbow, damage to the nerve may extend into the upper arm; there is some support for this in the fact that in a few of the patients the electrical threshold of the nerve trunk was appreciably raised for several centimetres above the ulnar groove. However, there are almost certainly other factors concerned as it is known that nerve conduction in the upper arm is slightly reduced even when the lesion is at the wrist or in the hand. This has been noted not only for lesions of the deep branch of the ulnar nerve in the palm (Ebeling et al., 1960) but $\vec{N}$ also for median nerve compression at the wrist and ${ }^{\circ}$ O after nerve suture at this level (Gilliatt and Thomas $\frac{O}{\mathbb{0}}$ to be published).

When motor latency is measured from the stimuluse artefact to the initial deflection of the muscle action potential, the figure obtained must obviously apply to the most rapidly conducting fibre present and even if the majority of fibres in a nerve trunk are affected by a partial lesion, slowing will not be detected if a single normal fibre survives. This may explain the normal motor conduction velocity found in one of our patients (Case VI) with an established ulnar nerve lesion. For this reason, the direct recording of nerve action potentials is of particular importance in patients with normal motor latencies. When the finger is stimulated the nerve action potential recorded at the wrist is due to an afferent volley in sensory fibres alone, but with stimulation of the nerve trunk at the wrist or above, an antidromic volley is also set up in motor fibres; thus with wrist stimulation, absence of a recordable action potential above the elbow may be accepted as indicating a disturbance of both motor and sensory conduction. It was emphasized by Gilliatt and Sears (1958) that the recording of a nerve action potential depended upon the passage of a synchronous volley of impulses under the recording electrodes and that loss of the action potential could be due to dispersion of the volley. Dispersion of the ascending volley may well explain our inability to record a nerve action potential above the elbow 
when stimulating the wrist in Case VI, although maximal motor velocity over the same segment was within normal limits. Dispersion of the afferent volley may also explain the absence of a nerve action potential at the wrist in one patient (Case XIV), in whom sensation in the ulnar fingers was intact on formal clinical testing.

The recording of nerve action potentials from the axilla with stimulation above the elbow has been introduced in order to define the upper level of the lesion in cases without a clear-cut abnormality of motor conduction. Technically this has proved more difficult and time-consuming than the other procedures which we have used, but in each of the six cases in which it was tried we were able to demonstrate an ascending volley in the upper arm whereas none could be detected below this level. In two cases the axillary potentials were smaller than those seen .in control subjects; this again suggests that conduction may be mildly disturbed above the level of a chronic lesion.

In this paper we have deliberately confined our attention to patients in whom the diagnosis was firmly established on clinical grounds. Thus the patients we have described have all had relatively severe lesions. It may be asked whether useful information can also be expected from nerve conduction studies in patients with mild ulnar nerve lesions or in cases in which the diagnosis is in doubt. In this respect our own experience has been encouraging; in patients with frank muscle wasting we have usually been able to demonstrate some slowing of motor conduction and in those without wasting the direct recording of nerve action potentials has proved particularly valuable. As an example of this, a patient (Mr. G. S.) described by Gilliatt and Sears (1958) may be cited. In this case there was mild weakness without wasting in the hand with minimal sensory loss; the ulnar nerve was not thickened and the elbow joint was normal. However, when the ulnar nerve was stimulated at the wrist only a trace of the normal nerve action potential above the elbow was seen, whereas a normal result was obtained when the median nerve was examined in the same way.

In contrast to this, it should be emphasized that we have never observed any abnormality of ulnar nerve conduction in patients with complaints of pain or paraesthesiae but without physical signs on clinical examination. Thus it is our impression that conduction studies are not likely to be helpful in localizing the level of an ulnar nerve lesion unless the degree of nerve damage is sufficient to produce definite impairment of power or sensation in the hand.

\section{Summary}

Conduction in the ulnar nerve has been examined in 14 patients with chronic lesions at the level of the elbow, and the results have been compared with those obtained in a similar number of control subjects.

In order to examine conduction in motor fibres, the ulnar nerve was stimulated just above the wrist and elbow and in the axilla, the muscle response being recorded from the abductor digiti minimi or the first dorsal interosseous muscle. Slowing of motor nerve conduction was present in 13 of the 14 patients with ulnar lesions, the changes being most marked in the forearm and elbow region.

In most of the patients afferent conduction was also examined by stimulating the ulnar nerve trunk and recording the action potential of the afferent volley at a higher level in the arm. This proved to be a reliable technique in control subjects. In patients with ulnar lesions, no action potentials could be recorded from the nerve above the elbow with wrist stimulation, or from the wrist when the digital nerves of the fifth finger were stimulated. With stimulation above the elbow, however, nerve action potentials were recorded successfully from the axilla in every case in which this was attempted.

It is suggested that in patients with suspected ulnar nerve lesions the use of these procedures may be of assistance in establishing the site of nerve damage.

We wish to thank members of the staff of the National Hospitals for Nervous Diseases who have referred patients for investigation. Case III was referred from St. Mary's Hospital and we are most grateful to Dr. Harold Edwards and Mr. George Bonney for referring the patient and for permission to quote from their clinical notes. We are indebted to Dr. Ritchie Russell for referring Case XIV and our thanks are due to the staff of the Military Hospital, Wheatley, for their help in providing clinical details of this case.

We also wish to thank Dr. W. A. Cobb and Mr. T. A. Sears for helpful criticism and advice, and Mr. H. B. Morton for technical assistance.

\section{REFERENCES}

Dawson, G. D. (1956). J. Physiol. (Lond.), 131, 436. and Scott, J. W. (1949). J. Neurol. Neurosurg. Psychiat.,

Ebeling, P., Gilliatt, R. W., and Thomas, P. K. (1960). Ibid., 23, 1. Gilliatt, R.' W., and Sears,'T. A. (1958). Ibid., 21, 109

Norris, A. H., Shock, N.'W., and Wagman, I. H. (1953). J. appl. Physiol, 5, 589 .

ord, J. W. B. (1958). M.S. Thesis (Phys. Med.), Univ. of Minnesota.

Simpson, J. A. (1956). J. Neurol. Neurosurg. Psychiat., 19, 275. Thomas, P. K., Sears, T. A., and Gilliatt, R. W. (1959). Ibid., 22, 175. 


\section{A P P E N D I X}

\begin{tabular}{|c|c|c|c|c|c|c|c|c|c|}
\hline $\begin{array}{l}\text { Case } \\
\text { No. }\end{array}$ & E.M.G. No. & Age & Sex & \begin{tabular}{|c|}
$\begin{array}{c}\text { Duration } \\
\text { of } \\
\text { Symptoms } \\
\text { (in months) }\end{array}$ \\
\end{tabular} & $\begin{array}{l}\text { Wasting } \\
\text { of } \\
\text { Hand } \\
\text { Muscles }\end{array}$ & $\begin{array}{c}\text { Sensory } \\
\text { Loss }\end{array}$ & $\begin{array}{l}\text { Flexor } \\
\text { Digitorum- } \\
\text { Profundus } \\
\text { III and IV }\end{array}$ & $\begin{array}{l}\text { Radiography } \\
\text { of } \\
\text { Elbow Joint }\end{array}$ & Operative Findings \\
\hline I & 24071 & 53 & $\mathbf{M}$ & 3 & ++ & + & Normal & $\begin{array}{l}\text { Marked osteo- } \\
\text { arthritic changes }\end{array}$ & $\begin{array}{l}\text { Nerve obviously thickened with } \\
\text { ganglio-form swelling behind }\end{array}$ \\
\hline II & 30616 & 53 & $\mathbf{M}$ & 36 & ++ & + & Affected & $\begin{array}{l}\text { Old fracture with } \\
\text { deformity and }\end{array}$ & $\begin{array}{l}\text { No operation } \\
\text { Nerve thickened on palpation }\end{array}$ \\
\hline III & 31474 & 60 & $\mathbf{M}$ & 4 & $++t$ & ++ & Affected & $\begin{array}{l}\text { Marked osteo- } \\
\text { arthritic changes }\end{array}$ & $\begin{array}{l}\text { Constriction of nerve by fibrous } \\
\text { origin of flexor carpi ulnaris } \\
\text { with neuromatous thickening } \\
\text { above }\end{array}$ \\
\hline IV & 31939 & 65 & $\mathbf{M}$ & 3 & + & + & Affected & $\begin{array}{l}\text { Osteo-arthritic } \\
\text { changes }\end{array}$ & $\begin{array}{l}\text { No operation } \\
\text { Nerve thickened on palpation }\end{array}$ \\
\hline v & 32267 & 53 & $\mathbf{M}$ & 9 & + & + & Doubtful & $\begin{array}{l}\text { Osteo-arthritic } \\
\text { changes }\end{array}$ & $\begin{array}{l}\text { Nerve rather broad and firmly } \\
\text { adherent to groove }\end{array}$ \\
\hline VI & 31710 & 69 & $\mathbf{M}$ & 24 & ++ & ++ & Doubtful & $\begin{array}{l}\text { Marked arthritic } \\
\text { changes with loss } \\
\text { of joint space }\end{array}$ & $\begin{array}{l}\text { No operation } \\
\text { Nerve thickened on palpation }\end{array}$ \\
\hline$\underset{\text { VIII }}{\text { VII }}$ & $\begin{array}{l}27570 \\
32280\end{array}$ & $\begin{array}{l}33 \\
41\end{array}$ & $\begin{array}{l}\mathbf{F} \\
\mathbf{M}\end{array}$ & $\begin{array}{r}12 \\
3\end{array}$ & + & + & $\begin{array}{l}\text { Affected } \\
\text { Affected }\end{array}$ & $\begin{array}{l}\text { Normal } \\
\text { Osteo-arthritic }\end{array}$ & $\begin{array}{l}\text { Nerve much thickened } \\
\text { Neuromatous thickening }\end{array}$ \\
\hline IX & 34035 & 43 & $\mathbf{M}$ & 5 & $++t$ & $+t$ & Affected & $\begin{array}{l}\text { Osteo-arthritic } \\
\text { changes }\end{array}$ & $\begin{array}{l}\text { Considerable thickening of nerve } \\
\text { in region of condyle }\end{array}$ \\
\hline $\mathbf{x}$ & 24658 & 56 & $\mathbf{M}$ & 6 & ++ & ++ & Affected & $\begin{array}{l}\text { Old fracture with } \\
\text { deformity and } \\
\text { osteo-arthritis }\end{array}$ & $\begin{array}{l}\text { Nerve broadened, flattened and } \\
\text { discoloured }\end{array}$ \\
\hline $\mathbf{X I}$ & 34792 & 52 & $\mathbf{M}$ & 6 & ++ & + & Normal & A few osteophytes & $\begin{array}{l}\text { No operation } \\
\text { Nerve thickened on palpation }\end{array}$ \\
\hline $\begin{array}{l}\text { XII } \\
\text { XIII }\end{array}$ & $\begin{array}{l}28655 \\
33404\end{array}$ & $\begin{array}{l}68 \\
40\end{array}$ & $\begin{array}{l}\mathbf{M} \\
\mathbf{M}\end{array}$ & $\begin{array}{r}3 \\
18\end{array}$ & $\begin{array}{l}++ \\
++\end{array}$ & + & $\begin{array}{l}\text { Doubtful } \\
\text { Affected }\end{array}$ & $\begin{array}{l}\text { Normal } \\
\text { Old fracture with } \\
\text { gross deformity }\end{array}$ & $\begin{array}{l}\text { Nerve thickened } \\
\text { Nerve splayed out, thickened, and } \\
\text { surrounded by fibrous tissue }\end{array}$ \\
\hline XIV & 32770 & 20 & $\mathbf{M}$ & 7 & ++ & None & Normal & $\begin{array}{l}\text { Old fracture with } \\
\text { mild deformity }\end{array}$ & $\begin{array}{l}\text { Local constriction of nerve by } \\
\text { deep fascia between olecranon } \\
\text { and medial epicondyle }\end{array}$ \\
\hline
\end{tabular}

